\title{
ACKNOWLEDGMENTS
}

I've wanted to write this book since I was sixteen, and it would not have been possible without the people who sustained and blessed me with their help. ;Gracias, mi gente!

My dad, Ing. Aníbal Acosta Ayala bravely read the entire manuscript in record time. The book has an introduction thanks to the impressive editing skills and dedication of my boyfriend, the Honorable William $\mathrm{H}$. Abrashkin. My daughter, Amanda Cesarano, cheered me on throughout. The book proposal would not have seen the light of day without my dear friend (once student) Dr. Jessica Jiménez.

Clark University has nurtured and supported my entire career. Two provosts, Fred Greenaway and David Angel (who is now Clark's extraordinary president) gave me their steadfast support and academic guidance. My thinking has been profoundly impacted by the work of Clark's Higgins School of Humanities, which, under the leadership of Sarah Buie and Amy Richter, encourages a broad community of dialogue. Our wonderful librarians, Irene Walch, Mary Hartman, Holly Howes, and Rachael Shea, succored my research more times than I can say. Clark's information technology crew, especially Gregory Geiger and Cheryl Elwell Turner, saw to it that all possible tech support and tools were at my disposal.

The Foreign Languages \& Literatures Department, particularly Alice Valentine, Robert D. Tobin, Marvin D'Lugo, and Juan Pablo Rivera, helped me develop the guiding ideas about nationhood at the heart of the book. I could not have been chair of the department and written the 
book at the same time without Dilma Lucena, our fearless department manager, who kept me on track, kept me sane.

My ideas and readings grew and expanded through interactions with my students in the "Caribbean Literatures" and "The National Imagination" courses, among others. With their happy curiosity, dogged search for meaning, and their patience with a professor prone to wild tangents, they made our shared discoveries and love of culture all the more productive and enjoyable.

Leslie Mitchner and Lisa Boyajian of Rutgers University Press and Tim Roberts and Susan Murray of the American Literatures Initiative shepherded and steered the book to the final product. Alison Russo heroically indexed its contents.

And finally, to my Facebook friends, family, and colleagues, thanks for keeping me up to date on life in our beloved island.

My love and gratitude to you all.

\section{Note on Text}

All translations in this book are my own. I have included the Spanish originals of works of creative writing for the enjoyment of bilingual readers. 
Dream Nation 
